\title{
THE
}

\section{Characterizing Solid Electrolyte Interphase on Sn Anode in}

\section{Lithium Ion Battery}

\author{
Daniel M. Seo \\ University of Rhode Island \\ Cao Cuong Nguyen \\ University of Rhode Island \\ Benjamin T. Young \\ University of Rhode Island \\ David R. Heskett \\ University of Rhode Island, dheskett@uri.edu \\ Joseph C. Woicik
}

See next page for additional authors

Follow this and additional works at: https://digitalcommons.uri.edu/chm_facpubs

Creative Commons License

(c) (i)

This work is licensed under a Creative Commons Attribution 4.0 License.

\section{Citation/Publisher Attribution}

Seo, D. M., Nguyen, C. C., Young, B. T., Heskett, D. R., Woicik, J. C., \& Lucht, B. L. (2015). Characterizing Solid Electrolyte Interphase on Sn Anode in Lithium Ion Battery. J. Electrochem. Soc., 162(13), A7091-7095. doi: 10.1149/2.0121513jes Available at: http://dx.doi.org/10.1149/2.0121513jes 


\section{Authors}

Daniel M. Seo, Cao Cuong Nguyen, Benjamin T. Young, David R. Heskett, Joseph C. Woicik, and Brett L. Lucht 


\title{
Characterizing Solid Electrolyte Interphase on Sn Anode in Lithium Ion Battery
}

\author{
Daniel M. Seo, ${ }^{a}$ Cao Cuong Nguyen, ${ }^{a, *}$ Benjamin T. Young, ${ }^{b}$ David R. Heskett, ${ }^{\text {b }}$ \\ Joseph C. Woicik, ${ }^{\mathrm{c}}$ and Brett L. Lucht ${ }^{\mathrm{a}, * *, \mathrm{z}}$ \\ ${ }^{a}$ Department of Chemistry, University of Rhode Island, Kingston, Rhode Island 02881, USA \\ ${ }^{b}$ Department of Physics, University of Rhode Island, Kingston, Rhode Island 02881, USA \\ ${ }^{c}$ National Institute of Standards and Technology, Gaithersburg, Maryland 20899, USA
}

\begin{abstract}
Tin ( $\mathrm{Sn}$ ) nanoparticle electrodes have been prepared and battery cycling performance has been investigated with $1.2 \mathrm{M}$ LiPF 6 in ethylene carbonate (EC) / diethyl carbonate (DEC) electrolyte $(1: 1, \mathrm{w} / \mathrm{w})$ with and without added vinylene carbonate (VC) or fluoroethylene carbonate (FEC). Incorporation of either VC or FEC improves the capacity retention of Sn nanoparticle electrodes although incorporation of $\mathrm{VC}$ also results in a significant increase in cell impedance. The best electrochemical performance was observed with electrolyte containing $10 \%$ of added FEC. In order to develop a better understanding of the role of the electrolyte in capacity retention and solid electrolyte interface (SEI) structure, ex-situ surface analysis has been performed on cycled electrodes with infrared (IR) spectroscopy, X-ray photoelectron spectroscopy (XPS), and Hard XPS (HAXPES). The ex-situ analysis reveals a correlation between electrochemical performance, electrolyte composition, and SEI structure.

(C) The Author(s) 2015. Published by ECS. This is an open access article distributed under the terms of the Creative Commons Attribution 4.0 License (CC BY, http://creativecommons.org/licenses/by/4.0/), which permits unrestricted reuse of the work in any medium, provided the original work is properly cited. [DOI: 10.1149/2.0121513jes] All rights reserved.
\end{abstract}

Manuscript submitted June 19, 2015; revised manuscript received July 28, 2015. Published August 26, 2015. This paper is part of the JES Focus Issue on Electrochemical Interfaces in Energy Storage Systems.

Graphite has been widely used as an anode material in lithium ion batteries. However, there is significant interest in increasing the energy density of lithium ion batteries for electric vehicle applications. ${ }^{1}$ One method of current interest for increasing the energy density of lithium ion batteries includes the use of high capacity metal alloy anode materials, such as silicon $(\mathrm{Si})$ and tin $(\mathrm{Sn}) .^{2-6} \mathrm{Sn}$ has almost three times more capacity $(944 \mathrm{mAh} / \mathrm{g})$ than graphite $(372 \mathrm{mAh} / \mathrm{g})$. However, a major challenge for the use $\mathrm{Sn}$ as an anode material is the large volume expansion/contraction during lithium insertion and extraction. The large surface area changes result in damage to the anode solid electrolyte interface (SEI) and continuous decomposition of the electrolyte. There have been many investigations of novel fabrication methods for Sn-based anodes to mitigate the problems with the SEI due to the volume changes. ${ }^{2,7-9}$ However, few investigations have focused on developing a better understanding of SEI formation on Sn anodes. ${ }^{10-12}$ In order to develop $\mathrm{Sn}$ anodes for lithium ion batteries, a better understanding of the structure and function of the SEI on Sn is required.

In this investigation, $\mathrm{Sn}$ nanoparticle electrodes were prepared and tested with different electrolytes. A standard electrolyte composed of 1.2 $\mathrm{M} \mathrm{LiPF}_{6}$ in EC/DEC with and without 5 or $10 \%$ of the SEI film forming additives FEC or VC has been investigated for optimization of an electrolyte formulation for Sn electrodes. ${ }^{13}$ The cells have been analyzed via electrochemical cycling and electrochemical impedance spectroscopy. In order to develop a better understanding of the role of the electrolyte in SEI formation and stability, the Sn nanoparticle electrodes were extracted from cells and ex-situ surface analysis with infrared with attenuated total reflectance (IR-ATR), X-ray photoelectron spectroscopy (XPS) and Hard XPS (HAXPES) was conducted. While IR-ATR and XPS are frequently utilized analytical techniques for the investigation of the SEI, ${ }^{14}$ HAXPES has been less utilized due to the need for synchrotron radiation. ${ }^{15,16}$

HAXPES can be used to develop a better understanding of the role of different solvents in SEI structure and composition. The high photon energies available at synchrotrons (compared with lab sources) significantly increase the probing depth of core level photoemission. As the kinetic energy of the outgoing photoelectrons increases, the

\footnotetext{
*Electrochemical Society Student Member.

**Electrochemical Society Active Member.

${ }^{\text {z} E-m a i l: ~ b l u c h t @ c h m . u r i . e d u ~}$
}

mean free path increases as well. Therefore with the HAXPES technique the elemental composition of thin films such as SEI layers can be probed to greater depths than are available with conventional XPS systems.

The cells with the best electrochemical performance contain electrolyte with $10 \%$ FEC. The ex-situ analysis of the SEI suggests that the improved performance is due to an increased stabilization of the SEI by a combination of polymer and inorganic lithium salts.

\section{Experimental}

Sn nanoparticles (60-80 nm, 99.99\%) were obtained from a commercial supplier. Sn nanoparticles were mixed with super C, poly(acrylic acid) (PAA, 450,000 MW) and sodium carboxymethyl cellulose (CMC, 700,000 MW) in distilled water with a weight ratio of $70: 15: 7.5: 7.5$. The well-mixed slurry was coated on a copper foil and dried in the air at room temperature for 1 hour and then dried under vacuum overnight. Electrodes were punched into $12.7 \mathrm{~mm}$ diameter disks and dried at $150{ }^{\circ} \mathrm{C}$ for 24 hours in a vacuum oven. The total mass of active material ( $\mathrm{Sn})$ is $\sim 0.8 \mathrm{mg} / \mathrm{cm}^{2}$.

Battery grade ethylene carbonate (EC), diethyl carbonate (DEC), fluoroethylene carbonate (FEC), vinylene carbonate (VC) and lithium hexafluorophosphate $\left(\mathrm{LiPF}_{6}\right)$ were used as received. The electrolyte formulations, combinations of salt, solvent, and additives, were prepared in an Ar-filled glove box. The concentrations of additives are presented as weight percentages. 2032 coin cells were prepared in an Ar filled glove box for electrochemical performance evaluation and ex-situ surface analyses of the electrodes. These cells consist of a composite $\mathrm{Sn}$ anode as the working electrode, lithium metal disk as the counter/reference electrode, one polyolefin and one GF/D glass fiber as separators, and $100 \mu \mathrm{l}$ of electrolyte. Cells were cycled between 0.05 and $1.50 \mathrm{~V}$ at a rate of $\mathrm{C} / 20$ for first 3 cycles and $\mathrm{C} / 3$ for additional 50 cycles at $25{ }^{\circ} \mathrm{C}$ using commercial battery cyclers. All cells were built in triplicate. Representative data is presented. After the $50^{\text {th }}$ de-lithiation, cells were rested for $16 \mathrm{hrs}$ and electrochemical impedance spectroscopy (EIS) was recorded using a potentiostat with an amplitude of $10 \mathrm{mV}$ and frequency range of $300 \mathrm{kHz}-20 \mathrm{mHz}$.

The electrodes were collected after cycling and rinsed with DMC three times to remove residual electrolyte. The infrared spectra with attenuated total reflectance (IR-ATR) were collected with a 
commercial instrument equipped with LaDTG detector in a $\mathrm{N}_{2}$ glove box. Spectra were acquired with 512 scans and the spectral resolution was $4 \mathrm{~cm}^{-1}$. X-ray photoelectron spectroscopy (XPS) was performed using a commercial spectrometer with an $\mathrm{Al} \mathrm{K}_{\alpha} \mathrm{X}$-ray source and spot size of $400 \mu \mathrm{m}$. Flood gun was turned on to compensate charging effect during measurement. Samples were transferred from the glove box to XPS analysis chamber using a special designed vacuumsealed-transfer unit without exposure to the air at any time. The binding energy was corrected using the $\mathrm{C} 1 \mathrm{~s}$ peak for hydrocarbon at $285 \mathrm{eV}$.

The HAXPES measurements were carried out at the NIST beamiline X24A at the National Synchrotron Light Source at Brookhaven National Laboratory. The beamline contains a double Si(111) crystal monochromator with a photon energy range of $\sim 2.1-6.0 \mathrm{keV}$. The electron energy analyzer is a hemispherical analyzer, which was operated in transmission mode at a pass energy of $500 \mathrm{eV}$, yielding an overall energy resolution of $0.45 \mathrm{eV}$ at $2200 \mathrm{eV}$ and $0.55 \mathrm{eV}$ at $5000 \mathrm{eV}$. Photoemitted 2p electrons from an Ag foil were used to calibrate the photon energy. The samples were positioned near grazing incidence with respect to the photon beam and near normal to the analyzer axis.

The electrodes were rinsed in an argon glove box, attached to a sample holder and sealed in Ar for transportation to Brookhaven National Lab. The sample bar containing all samples was then installed in the experimental chamber through an $\mathrm{N}_{2}$ glove bag. The HAXPES measurements consist of a series of core levels at incident photon energies of 2200 and $5000 \mathrm{eV}$. The binding energy for all spectra were also corrected using the C 1s peak for hydrocarbon at $285 \mathrm{eV}$. All spectra for each single core level and photon energy were also normalized to the background and offset for display and comparison purposes.

\section{Results and Discussion}

Electrochemical behavior- - The electrochemical cycling performance of $\mathrm{Sn}$ nanoparticle/Li coin cells with different electrolytes is presented in Figure 1. With the standard electrolyte (1.2 $\mathrm{M} \mathrm{LiPF}_{6}$ in EC/DEC, 1:1, w:w) a significant decrease in capacity is observed between cycles 5 and 20 . Only $25 \%$ of the initial capacity was retained after the first 20 cycles. Related poor columbic efficiency is observed during the first 20 cycles. The low efficiency probably is due to severe electrolyte decomposition and electrode structure disintegration. Incorporation of 5 or $10 \%$ of the anode SEI film forming additive, FEC, results in a significant improvement in both capacity retention and coulombic efficiency. The first cycle efficiencies for cells cycled with added FEC or VC are slightly lower than the standard electrolyte due to the reduction of FEC or VC to form a protective SEI on the tin electrodes. Cells containing $5 \%$ of $\mathrm{VC}$ had better performance than the standard electrolyte but poorer performance than the electrolyte with added FEC, while cells containing $10 \%$ VC had very poor capacity retention.

Electrochemical impedance spectroscopy.- Electrochemical impedance spectroscopy has been conducted on $\mathrm{Sn}$ nanoparticle/Li cells at the end of de-lithiation after 50 cycles with different electrolytes (Figure 2). The electrochemical impedance is very similar for the cells cycled with the standard electrolyte and electrolyte containing both 5 and $10 \%$ FEC. The cells containing electrolyte with $5 \%$ added VC have significantly higher impedance than the cells with standard electrolyte, consistent with the observation on graphite and silicon nanoparticle anodes. ${ }^{13,17}$ Thus, while incorporation of $5 \%$ VC improves capacity retention, it also results in much greater cell resistance and therefore FEC is the preferable additive for $\mathrm{Sn}$ nanoparticle electrodes.

IR-ATR spectroscopy.- IR-ATR spectra have been collected for the fresh $\mathrm{Sn}$ nanoparticle electrode and $\mathrm{Sn}$ nanoparticle electrodes after the $50^{\text {th }}$ cycle with different electrolytes (Fig. 3). The IR spectrum of the fresh Sn nanoparticle electrode is dominated by the carboxylate
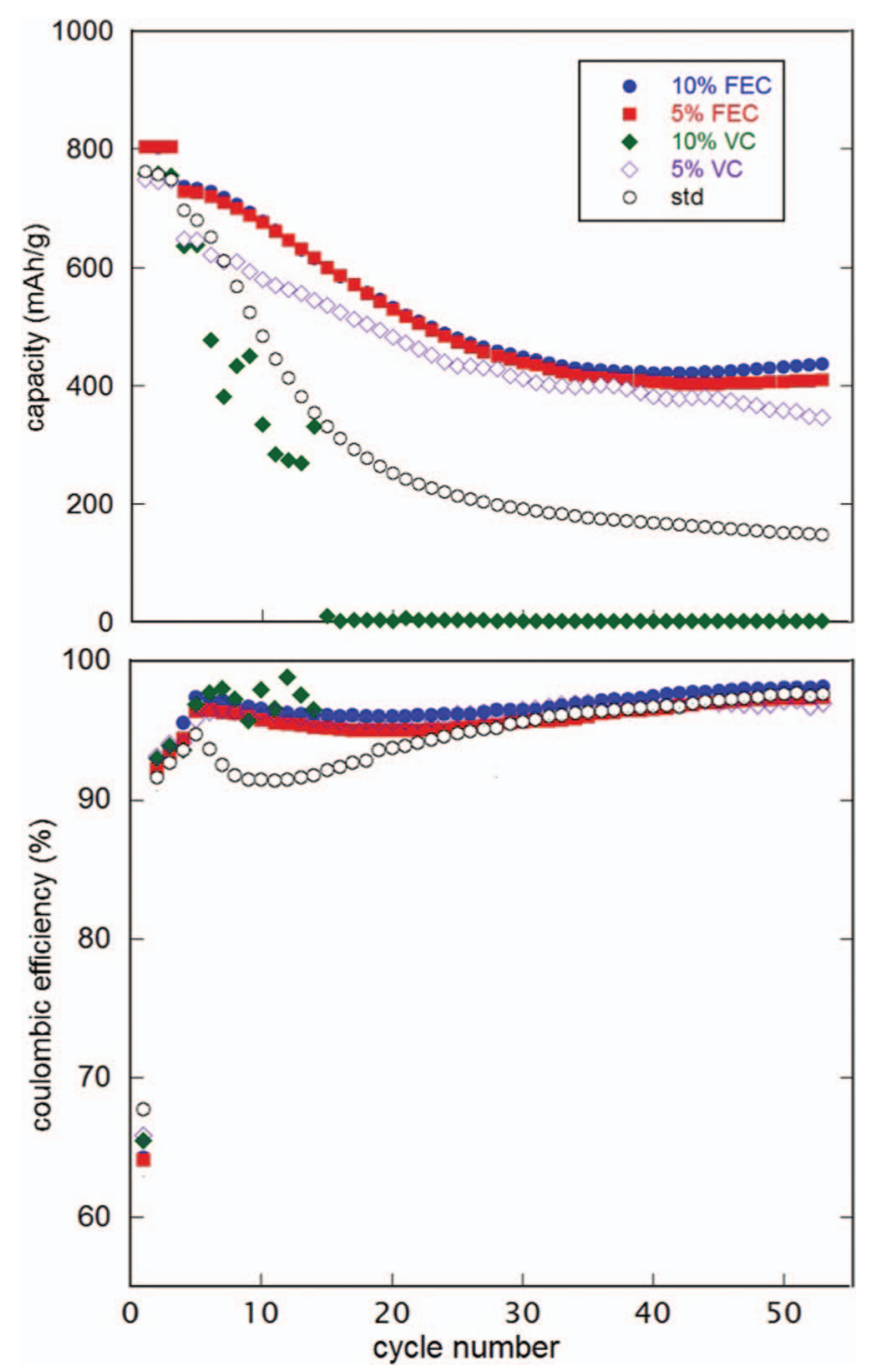

Figure 1. Plot of de-lithiation capacity (top, $\mathrm{mAh} / \mathrm{g}$ of $\mathrm{Sn}$ ) and columbic efficiency (bottom) vs. cycle number of Sn anode with different electrolytes.

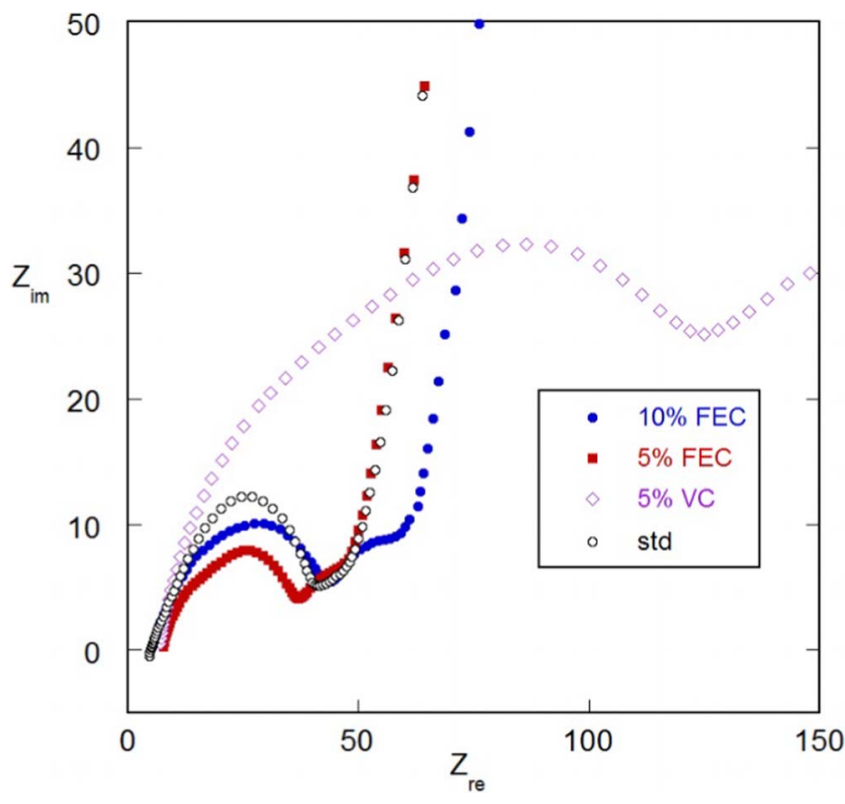

Figure 2. Electrochemical impedance spectra after $50^{\text {th }}$ cycle in different electrolytes. 


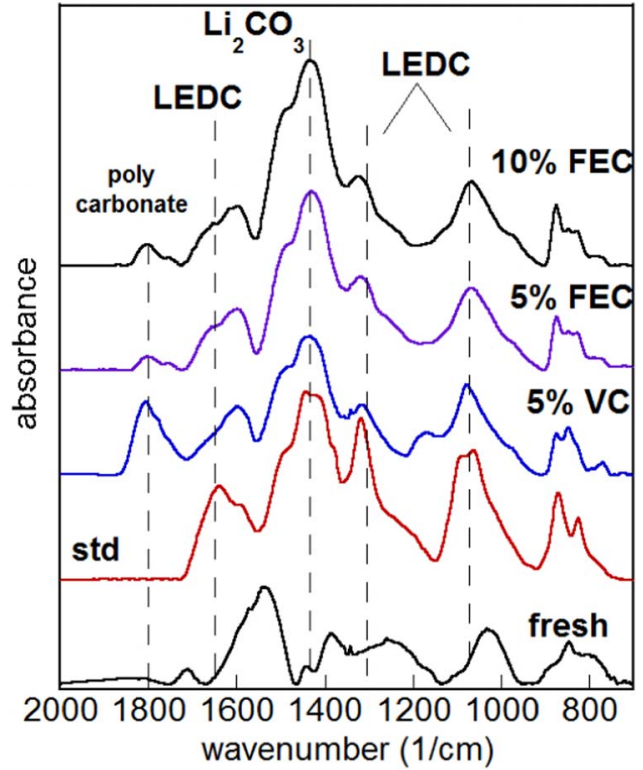

Figure 3. IR-ATR spectra of $\mathrm{Sn}$ anodes after $50^{\text {th }}$ cycle in different electrolytes.

absorption of the binder at $1560 \mathrm{~cm}^{-1}$. Upon cycling with the standard electrolyte significant changes are observed by IR spectroscopy consistent with the generation of a thick SEI on the surface of the
Sn nanoparticle electrodes. The IR spectrum of the Sn electrode cycled with the standard electrolyte has two primary components, absorptions are observed at $1650,1315,1050$ and $823 \mathrm{~cm}^{-1}$ consistent with the presence of lithium alkyl carbonates $\left(\mathrm{ROCO}_{2} \mathrm{Li}\right)^{18-20}$ and at 1485 and $1416 \mathrm{~cm}^{-1}$ consistent with the presence of lithium carbonate $\left(\mathrm{Li}_{2} \mathrm{CO}_{3}\right){ }^{11,17}$ The electrodes cycled with electrolyte containing added $\mathrm{VC}$ or FEC also contain absorptions characteristic of $\mathrm{ROCO}_{2} \mathrm{Li}$ and $\mathrm{Li}_{2} \mathrm{CO}_{3}$ although the ratio of $\mathrm{ROCO}_{2} \mathrm{Li}$ to $\mathrm{Li}_{2} \mathrm{CO}_{3}$ varies as a function of additive. In addition, a significant new absorption is observed at $1805 \mathrm{~cm}^{-1}$. The new absorption is characteristic of poly $(\mathrm{VC})^{17,21}$ or poly(FEC), ${ }^{13,20,22}$ respectively. The intensity of the peak at $1805 \mathrm{~cm}^{-1}$ is greatest for the electrode cycled with $5 \% \mathrm{VC}$ which is consistent with a thick layer of poly(VC) on the surface of the Sn nanoparticle electrode and correlates with the high observed impedance as discussed above. For the Sn electrode cycled in electrolyte containing FEC, the poly(FEC) peak increases with increasing concentration of FEC as expected. In addition, the intensity of the absorptions at 1485 and $1416 \mathrm{~cm}^{-1}$ increase with increasing concentration of FEC suggesting that the reduction of FEC generates additional $\mathrm{Li}_{2} \mathrm{CO}_{3}$. This agrees with previous investigations which suggest that the primary reduction products of EC and DEC are lithium alkyl carbonates, and reduction of $\mathrm{VC}$ and $\mathrm{FEC}$ generate poly(VC) and poly(FEC), respectively, along with $\mathrm{Li}_{2} \mathrm{CO}_{3} .{ }^{17,19-23}$

$X$-ray photoelecton spectroscopy (XPS).- High resolution XPS spectra are presented in Figure 4 for Sn nanoparticle electrodes cycled with standard electrolyte and electrolyte containing 10\% FEC after different numbers of cycles (Figure 4). The $\mathrm{C} 1 \mathrm{~s}$ spectrum of the fresh Sn electrode, has a peak at $284 \mathrm{eV}$ for the conductive carbon and peaks at 286 and $288 \mathrm{eV}$ for $\mathrm{C}-\mathrm{O}$ and $\mathrm{C}=\mathrm{O}$, respectively, from the PAA and
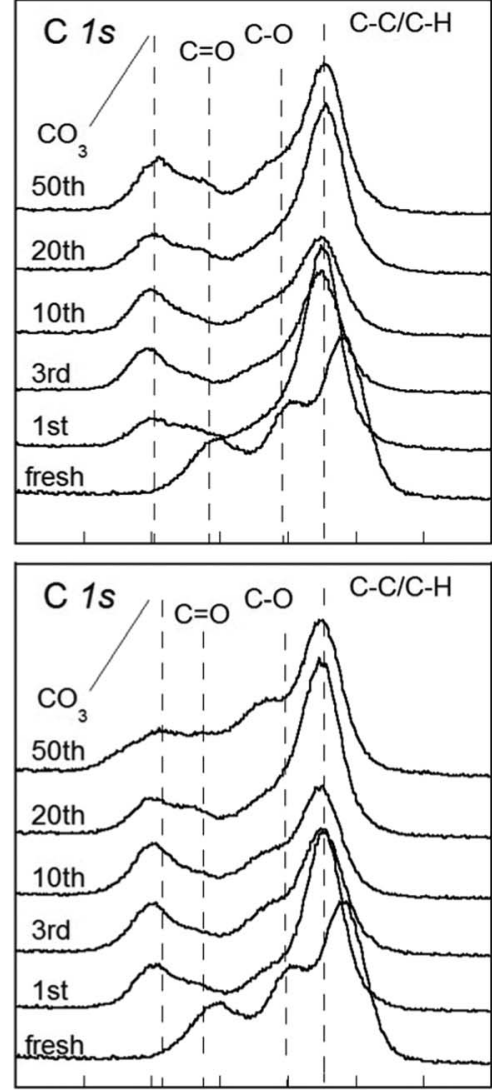

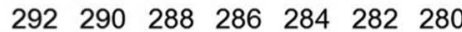
Binding Energy (eV)
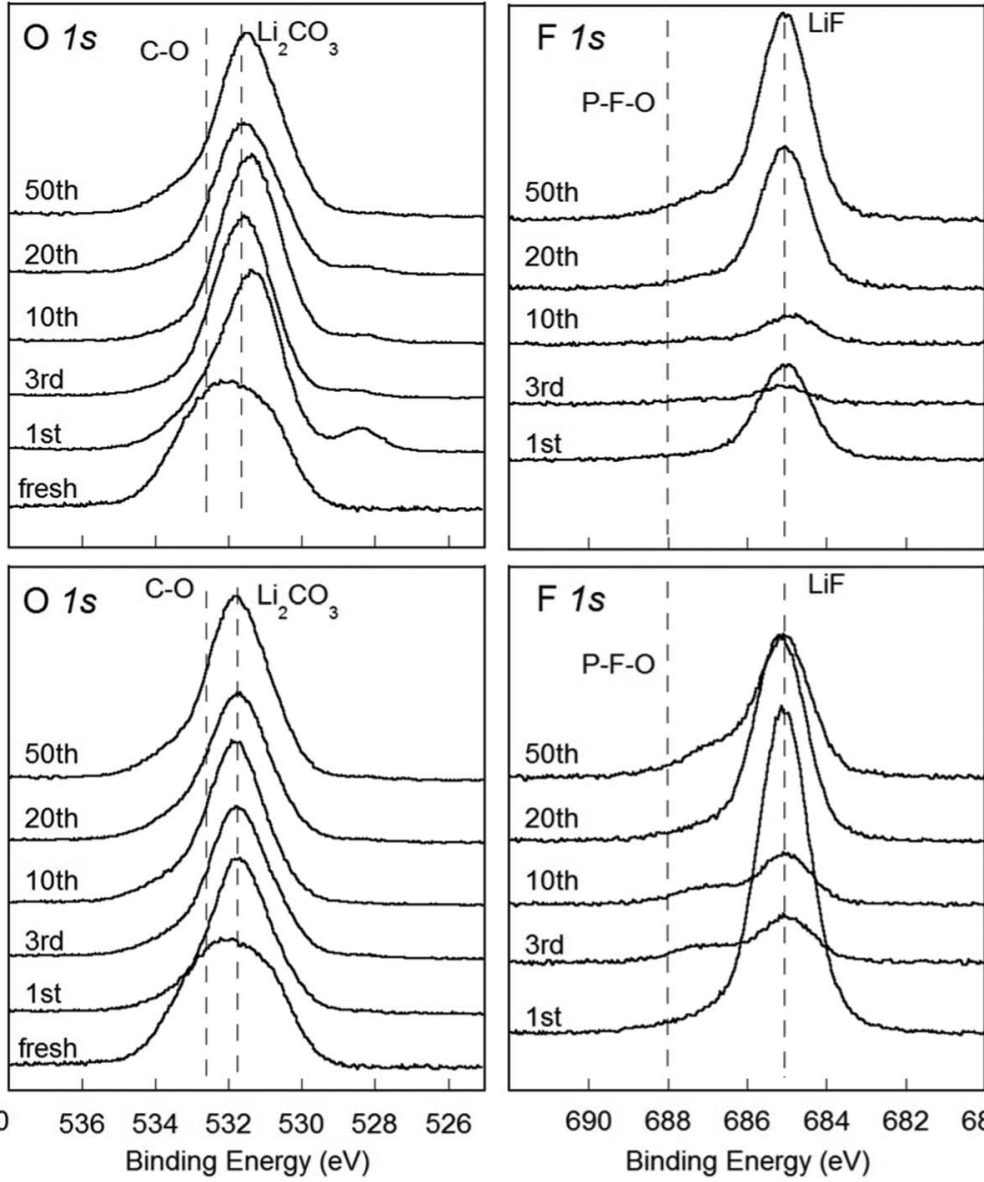

Figure 4. XPS spectra of Sn anode in different number of cycle with standard (top) and 10\% FEC containing electrolyte (bottom). 
Table I. Elemental concentration on surface of fresh and cycled Sn anode with standard and $10 \%$ FEC containing electrolyte obtained from commercial XPS $(1487 \mathrm{eV})$.

\begin{tabular}{ccccccc} 
std & fresh & $1^{\text {st }}$ & $3^{\text {rd }}$ & $10^{\text {th }}$ & $20^{\text {th }}$ & $50^{\text {th }}$ \\
\hline C & 50 & 42 & 41 & 36 & 42 & 39 \\
O & 44 & 48 & 55 & 59 & 43 & 42 \\
F & - & 10 & 3 & 4 & 14 & 18 \\
P & - & 0 & 1 & 1 & 1 & 1 \\
Sn & 6 & 0 & 0 & 0 & 0 & 0 \\
$10 \%$ FEC & fresh & $1^{\text {st }}$ & $3^{\text {rd }}$ & $10^{\text {th }}$ & $20^{\text {th }}$ & $50^{\text {th }}$ \\
\hline C & 50 & 38 & 46 & 41 & 42 & 47 \\
O & 44 & 33 & 46 & 53 & 38 & 37 \\
F & - & 28 & 7 & 5 & 19 & 15 \\
P & - & 1 & 1 & 1 & 1 & 1 \\
Sn & 6 & 0 & 0 & 0 & 0 & 0
\end{tabular}

$\mathrm{CMC}$ binders. The O1s spectrum contains a single broad peak at 533 $\mathrm{eV}$ from $\mathrm{SnO}_{x}$ and the $\mathrm{C}-\mathrm{O}$ and $\mathrm{C}=\mathrm{O}$ species in the $\mathrm{CMC}$ and PAA binders. ${ }^{15}$ After one cycle with both electrolytes, the $\mathrm{C} 1 \mathrm{~s}$ and $\mathrm{O} 1 \mathrm{~s}$ spectra are changed due to the formation of an SEI. The electrodes extracted from the cells after the first cycle with the standard electrolyte contain new peaks at $290 \mathrm{eV}$ for $\mathrm{C} 1 \mathrm{~s}$ and at $532 \mathrm{eV}$ for O1s characteristic of the $-\mathrm{CO}_{3}$ in lithium alkyl carbonates and $\mathrm{Li}_{2} \mathrm{CO}_{3}$ from the reduction of the carbonate solvents. ${ }^{19,20,14}$ Only small changes are observed to the $\mathrm{C} 1 \mathrm{~s}$ and $\mathrm{O} 1 \mathrm{~s}$ spectra with continued cycling. A new peak is also observed in the $\mathrm{F} 1 \mathrm{~s}$ spectrum at $685 \mathrm{eV}$ characteristic of $\mathrm{LiF}$ from the decomposition of $\mathrm{LiPF}_{6}$. Interestingly, the concentration of $\mathrm{F}$ is high after the first cycle, then decreases for cycles $3-10$, followed by an increase upon additional cycling. The changes in elemental concentrations of the SEI suggest that the SEI continues to evolve during the first 10 cycles while significant capacity fade is observed (Table I).

The XPS spectra of the electrodes extracted from cells cycled with electrolyte containing $10 \%$ FEC are similar to those with the standard electrolyte. The $\mathrm{C} 1 \mathrm{~s}$ and $\mathrm{O} 1 \mathrm{~s}$ spectra contain new peaks characteristic of lithium alkyl carbonates and lithium carbonate. Surprisingly, the high energy shoulder typically observed for poly(FEC) at $\sim 291.5 \mathrm{eV}$ is not present. The lack of an observed peak for poly(FEC) by XPS and the observation of a weak absorption by IR spectroscopy may be due to high intensity of the $\mathrm{C}=\mathrm{O}$ absorption in IR spectroscopy. The F 1s spectra are dominated by $\mathrm{LiF}$ at $685 \mathrm{eV}$, and the concentration of $\mathrm{F}$ is higher than observed for electrodes cycled with the standard electrolyte. As observed with the standard electrolyte, only small changes occur to the $\mathrm{C} 1 \mathrm{~s}$ and $\mathrm{O} 1 \mathrm{~s}$ spectra with increased cycling while the $\mathrm{F}$ concentration is lower for cycles 3-10 and then becomes greater when the capacity retention stabilizes during cycles $20-50$. The presence of higher concentrations of $\mathrm{F}$ for cells cycled with electrolytes containing FEC is likely due to the reduction of FEC generating additional $\mathrm{LiF}$ in the SEI on the surface of the Sn electrode. ${ }^{22-26}$ The SEI for cells cycled with electrolyte containing FEC has a similar evolution to the SEI for the cells cycled with the standard electrolyte, although the evolution results in significantly less capacity fade and related electrolyte decomposition (Table I). ${ }^{27}$

Hard XPS (HAXPES). - The C 1s core level HAXPES spectra of the cycled tin anode taken with photon energies of $1487 \mathrm{eV}$ (lab XPS), $2200 \mathrm{eV}$, and $5000 \mathrm{eV}$ are provided in Figure 5. The higher photon energies results in a greater depth of penetration and can provide depth dependent information of the composition of the SEI. The XPS spectra for both the standard electrolyte and the electrolyte with $10 \%$ FEC are similar for all photon energies. The spectra are dominated by $-\mathrm{CO}_{3}, \mathrm{C}-\mathrm{O}$, and $\mathrm{C}-\mathrm{H}$ peaks characteristic of lithium alkyl carbonates, $\mathrm{Li}_{2} \mathrm{CO}_{3}$ and the universal carbon contamination. The similarity of the spectra at all photon energies suggests that the composition of the organic components of SEI is homogeneous as a function of depth. This is similar to what has been reported for the initial SEI generated

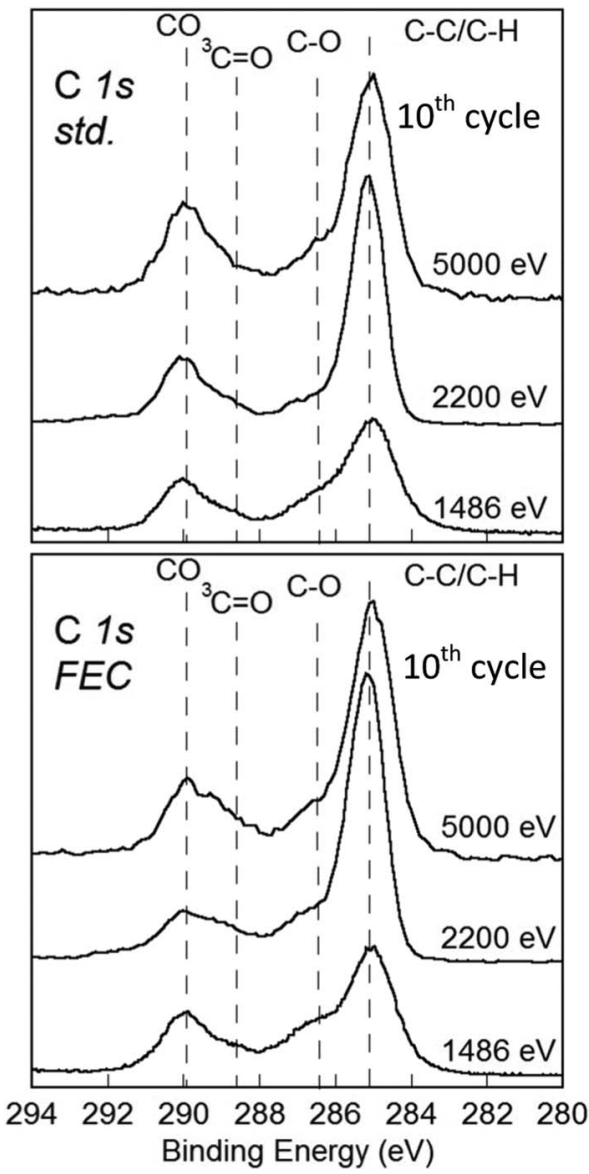

Figure 5. Hard X-Ray Photoelectron Spectra of Sn nanoparticle electrodes cycled with standard electrolyte (top) and electrolyte with 10\% of FEC (bottom).

on graphite, ${ }^{20}$ but different than that observed on $\mathrm{Si}$ where there is an inner and outer SEI which differ in composition. ${ }^{15,16}$ There are no Sn 3d peaks observed (not shown) for cycled electrodes at all photon energies and for both electrolytes suggesting the SEI is sufficiently thick to prevent the observation of low energy generated electrons from the underlying Sn surface.

\section{Conclusions}

The cycling performance of Sn nanoparticle electrodes in the presence of electrolytes with and without added VC or FEC has been conducted. Cells containing either 5 or $10 \%$ FEC have the best capacity retention and lowest electrochemical impedance. Ex-situ surface analysis of the Sn nanoparticle electrodes after cycling with different electrolytes reveals that modification of the electrolyte formulation changes the anode SEI. A schematic depiction of the SEI and tin nanoparticles is provided in Figure 6. Cells cycled with all electrolytes investigated contain lithium alkyl carbonates, $\mathrm{Li}_{2} \mathrm{CO}_{3}$, and $\mathrm{LiF}$ in the SEI. However, incorporation of $\mathrm{VC}$ results in an SEI which also has a high concentration of poly(VC) and the cell has high impedance. The SEI generated on the Sn nanoparticle electrode cycled with electrolyte containing FEC, contains low concentrations of poly(FEC), but higher concentrations of $\mathrm{Li}_{2} \mathrm{CO}_{3}$ and $\mathrm{LiF}$ than is observed for the standard electrolyte. The combination of a low concentration of polymer and high concentrations of inorganic lithium salts, $\mathrm{LiF}$ and $\mathrm{Li}_{2} \mathrm{CO}_{3}$, is likely responsible for the improved capacity retention, efficiency, and low impedance for cells cycled with electrolytes containing added FEC. 


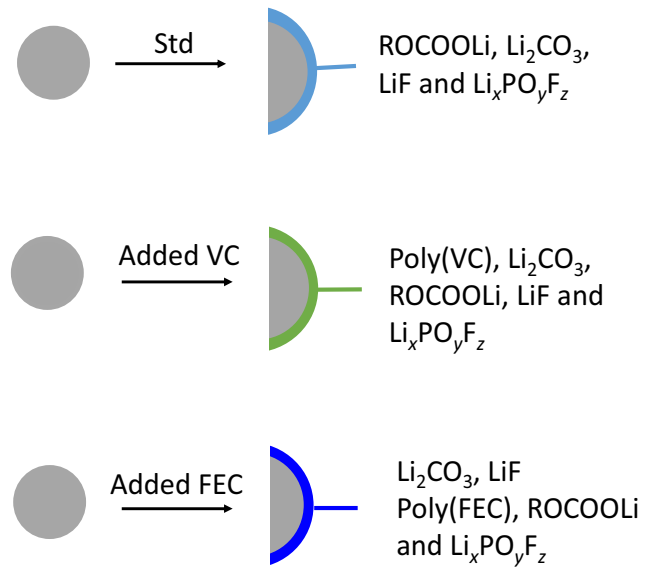

Sn

\section{After cycling}

Figure 6. Schematic depiction of SEI on tin nanoparticles with different electrolytes.

\section{Acknowledgment}

The authors gratefully acknowledge funding from Department of Energy Office of Basic Energy Sciences EPSCoR Implementation award (DE-SC0007074). Use of the National Synchrotron Light Source, Brookhaven National Laboratory, was supported by the U.S. Department of Energy, Office of Science, Office of Basic Energy Sciences, under Contract No. DE-AC02-98CH10886.

\section{References}

1. J. L. Tirado, Mater. Sci. Eng. R Rep., 40, 103 (2003).
2. M. Winter and J. O. Besenhard, Electrochimica Acta, 45, 31 (1999).

3. S.-C. Chao, Y.-C. Yen, Y.-F. Song, Y.-M. Chen, H.-C. Wu, and N.-L. Wu, Electrochem Commun., 12, 234 (2010).

4. E. Capacitors, M. Winter, and R. J. Brodd, Chem. Rev., 104, 4245 (2004).

5. R. A. Huggins, J. Power Sources, 81, 13 (1999).

6. C. J. Wen and R. A. Huggins, J. Electrochem. Soc., 128, 1181 (1981).

7. W.-J. Zhang, J Power Sources, 196, 13 (2011).

8. M. Wachtler, M. R. Wagner, M. Schmied, M. Winter, and J. O. Besenhard, J. Electroanal. Chem., 510, 12 (2001).

9. Z. Chen, L. Christensen, and J. R. Dahn, J. Electrochem. Soc., 150, A1073 (2003).

10. S. Park, J. Heon Ryu, S. M. Oh, and J. H. Ryu, J. Electrochem. Soc., 158, A498 (2011)

11. S.-W. Song and S.-W. Baek, Electrochimica Acta, 54, 1312 (2009).

12. R. Qiao, I. T. Lucas, A. Karim, J. Syzdek, X. Liu, W. Chen, K. Persson, R. Kostecki, and W. Yang, Adv. Mater. Interfaces, 1, 1300115 (2014).

13. C. C. Nguyen and B. L. Lucht, J. Electrochem. Soc., 161, A1933 (2014).

14. P. Verma, P. Maire, and P. Novák, Electrochimica Acta, 55, 6332 (2010).

15. B. Philippe, R. Dedryvère, J. Allouche, F. Lindgren, M. Gorgoi, H. Rensmo, D. Gonbeau, and K. Edström, Chem. Mater, 24, 1107 (2012).

16. B. Philippe, R. Dedryvère, M. Gorgoi, H. kan Rensmo, D. Gonbeau, K. Edström, and K. Edstro, Chem. Mater, 25, 394 (2013).

17. D. Aurbach, K. Gamolsky, B. Markovsky, Y. Gofer, M. Schmidt, and U. Heider, Electrochimica Acta, 47, 1423 (2002).

18. K. Xu, G. V. Zhuang, J. L. Allen, U. Lee, S. S. Zhang, P. N. Ross, and T. R. Jow, J. Phys. Chem. B, 110, 7708 (2006).

19. D. M. Seo, D. Chalasani, B. S. Parimalam, R. Kadam, M. Nie, and B. L. Lucht, ECS Electrochem. Lett., 3, A91 (2014).

20. M. Nie, D. P. Abraham, D. M. Seo, Y. Chen, A. Bose, B. L. Lucht, and D. Chalasani, J. Phys. Chem. C, 117, 13403 (2013).

21. H. Ota, Y. Sakata, A. Inoue, and S. Yamaguchi, J. Electrochem. Soc., 151, A1659 (2004).

22. V. Etacheri, O. Haik, Y. Goffer, G. A. Roberts, I. C. Stefan, R. Fasching, and D. Aurbach, Langmuir, 28, 965 (2011).

23. H. Nakai, T. Kubota, A. Kita, and A. Kawashima, J. Electrochem. Soc., 158, A798 (2011).

24. K. Leung, S. B. Rempe, M. E. Foster, Y. Ma, J. M. M. del la Hoz, N. Sai, and P. B. Balbuena, J. Electrochem. Soc., 161, A213 (2014).

25. R. Elazari, G. Salitra, G. Gershinsky, A. Garsuch, A. Panchenko, and D. Aurbach, J. Electrochem. Soc., 159, A1440 (2012).

26. I. A. Profatilova, C. Stock, A. Schmitz, S. Passerini, and M. Winter, J. Power Sources, 222, 140 (2013).

27. S. P. V. Nadimpalli, V. A. Sethuraman, S. Dalavi, B. Lucht, M. J. Chon, V. B. Shenoy, and P. R. Guduru, J. Power Sources, 215, 145 (2012). 